\title{
Obese Nulliparous Women and the Risk for Maternal and Fetal Complications
}

\author{
Hussein Attia Sharara1, Laman Naji Abdul Rhaman1, Firdous Ummunnisa1*, \\ Naseera Aboubaker1, Maisa Mohammed Abdullah', Nissar Shaikh² \\ ${ }^{1}$ Department of OBGY/NAH, Hamad Medical Corporation, Doha, Qatar \\ ${ }^{2}$ Surgical Intensive Care Unit (SICU), Hamad Medical Corporation, Doha, Qatar \\ Email: ${ }^{\text {fummunnisa@hmc.org.qa }}$
}

Received 27 January 2014; revised 20 February 2014; accepted 28 February 2014

Copyright (C) 2014 by authors and Scientific Research Publishing Inc.

This work is licensed under the Creative Commons Attribution International License (CC BY). http://creativecommons.org/licenses/by/4.0/

(c) (i) Open Access

\begin{abstract}
Obesity is becoming a global health care problem and an increasing number of obese female patients are getting pregnant. Aim of our study was to know the prevalence of obesity in nulliparous women and its impact on pregnancy as well as fetus. Patients and Methods: All nulliparous women with single pregnancy and gestational age of 37 weeks and above were included in the study. Primigradvida with multiple pregnancies, fetal abnormalities, and gestational age less than 37 weeks were excluded. Patients were divided into normal, overweight and obese group according to their prepragnancy body mass index (BMI). Results: Total 2243 nulliparous women were included in the study, majority $(56.8 \%)$ of patients were in the normal BMI group and only $24.8 \%$ were obese. But a significantly higher number of obese nulliparous women were in the age group of 18 to 29 years $(P<0.05)$. Comorbidities were significantly higher in obese primigravida. The incidence of gestational diabetes and pregnancy induced hypertension was significantly higher $(P<0.05)$ in obese nulliparous women. Overweight and obese nulliparous patients required significantly higher emergency caesarean section and assisted vaginal deliveries compared to the normal BMI nulliparous women $(P<\mathbf{0 . 0 3})$. Conclusion: Maternal obesity leads to prepartum, peripartum as well as fetal complication. Obese pregnant patients had a significant risk of developing gestational diabetes and pregnancy induced hypertension. In these patients the prevalence of assisted vaginal and cesarean deliveries is significantly high.
\end{abstract}

\section{Keywords}

Overweight; Obese Nulliparous; Gestational Diabetes; Pregnancy Induced Hypertension; Assisted Vaginal and Cesarean Deliveries

\footnotetext{
${ }^{*}$ Corresponding author.
} 


\section{Introduction}

Prevalence of obesity is rapidly increasing in local as well as international population hence the number of obese nulliparous women is also on rise [1]. In the United States of America about $29 \%$ of obese patients are in the reproductive age group (20 to 39 years) and recent literature showed that maternal pre-pregnancy obesity is associated with the increased risk for the pregnancy related complications and increased fetal morbidity [2].

It was an interesting but eye opening finding that the rate of cesarean deliveries increased in late nineties and early 2000. Apart from demographic changes, physician practice: the increased maternal weight had a significant impact on the increased rate of cesarean deliveries [3]. Aim of our study was to know the prevalence of surgical deliveries in obese nulliparous women and its impact on morbidity.

\section{Patients and Methods}

The study was conducted in a tertiary women's hospital. All nulliparous women with single pregnancy and gestational age of 37 weeks and above were included in the study. Nulliparous with fetal abnormalities, multiple pregnancies and cesarean deliveries due to malpresentation were excluded. Maternal body mass index, age, comorbidities, gestational diabetes, pregnancy induced hypertension, intrauterine growth retardation, gestational age of all nulliparous women was recoded retrospectively over a period of one year.

Nulliparous women were divided into three groups; Normal, overweight and obese depending upon their body mass index (BMI). Patients were included in normal group when their body mass index (BMI) was 19.8 to 26 $\mathrm{kg} / \mathrm{m}^{2}$, overweight when BMI was 26.1 to $29 \mathrm{~kg} / \mathrm{m}^{2}$ and obese nulliparous when the BMI of more than 29. Data was entered in SPSS program. Chi square test was used to compare the groups and a p value of less than 0.05 was considered as statistically significant.

\section{Results}

Two thousand two hundred forty three (2243) nulliparous women were included in the study. One thousand two hundred and seventy (1270) patients (56.8\%) had normal BMI, 415 (18.6\%) were overweight and 555 patients (24.8\%) were obese nulliparous women. A significant number of obese nulliparous $(\mathrm{P}<0.05)$ were in the age group of 18 to 29 years (Table 1). The comorbidities (bronchial asthma, anemia, chronic hypertension, and diabetes mellitus) were significantly higher in obese nulliparous (Table 1). Antenatal complications gestational diabetes mellitus, and pregnancy induced hypertension were also significantly higher $(\mathrm{P}<0.05)$ in obese nulliparous patients (Table 1). There was significant difference in method of delivery of normal, overweight and obese patients (Table 1$)$.

Statistically there was no significant difference in the gestational age of these patients (Table 1), but there was significantly higher incidence $(\mathrm{P}<0.03)$ of instrumental deliveries and emergency cesarean section in overweight and obese nulliparous women (Table 2). There was no significant difference $(\mathrm{P}<0.43)$ in indications for elective cesarean section in all three groups (Table 2). Obese nulliparous patients had a significantly higher $(\mathrm{P}<0.001)$ incidence of no progress of labor requiring emergency cesarean section (Table 2). Obese and overweight nulliparous also had significantly high rate of fetal distress $(\mathrm{P}<0.001)$ requiring emergency cesarean section (Table 2). Fetal birth weight was significantly higher in obese nulliparous compared to overweight and normal BMI $(\mathrm{P}<0.001)$ (Table 2).

\section{Discussion}

Obesity is rapidly becoming a significant health care problem all over the world [4]. Increasing number of obese patients are in the reproductive age. Obesity increases the risk of complication during pregnancy as well as after parturition.

Sebire et al. in their study found a significantly higher incidence of pre-eclampsia and gestational diabetes in obese pregnant patients [5]. Even in our study the incidence of gestational diabetes was significantly higher in obese pregnant nulliparous but the other significant finding was higher incidence of pregnancy induced hypertension.

Maternal obesity has been associated with higher rate of intrapartum meconium staining, cord accidents; these conditions can affect the decision about mode of delivery of the fetus [5] [6]. In our study the incidence of fetal distress, assisted vaginal delivery and cesarean section was significantly higher in obese parturient. This in- 
Table 1. Baseline characteristics of term, nulliparous women, according to their pre-pregnancy body mass index (BMI).

\begin{tabular}{|c|c|c|c|c|c|}
\hline Variable & $\begin{array}{c}\text { Normal BMI } \\
\text { N }=1273 \text { N (\%) }\end{array}$ & $\begin{array}{c}\text { Overweight BMI } \\
\mathrm{N}=415 \mathrm{~N}(\%)\end{array}$ & P-value & $\begin{array}{c}\text { Obese BMI } \\
\text { N = } 555 \text { N (\%) }\end{array}$ & P-value \\
\hline Method of delivery & $22.3 \pm 2.5$ & $27.5 \pm 0.8$ & $<0.001$ & $33.6 \pm 4.6$ & $<0.001$ \\
\hline \multicolumn{6}{|l|}{ Maternal age } \\
\hline$<18$ year & $13(1.0)$ & $3(0.7)$ & \multirow{3}{*}{0.789} & $8(1.4)$ & \\
\hline 18 - 29 year & $1030(80.9)$ & $333(80.2)$ & & 399 (71.9) & $<0.001$ \\
\hline$\geq 30$ year & $230(18.1)$ & $79(19.0)$ & & $148(26.7)$ & \\
\hline \multicolumn{6}{|l|}{ Antenatal complications } \\
\hline Gestational diabetes & $143(11.2)$ & $67(16.1)$ & 0.008 & $128(23.1)$ & $<0.001$ \\
\hline Pregnancy induced hypertension (P.I.H) & $59(4.6)$ & $23(5.5)$ & 0.455 & $53(9.5)$ & $<0.001$ \\
\hline Intrauterine growth retardation (IUGR) & $23(1.8)$ & $2(0.5)$ & - & $4(0.7)$ & 0.076 \\
\hline \multicolumn{6}{|l|}{ Chronic wound complications } \\
\hline Yes & $41(3.2)$ & $17(4.1)$ & \multirow[t]{2}{*}{0.395} & $39(7.0)$ & \multirow[t]{2}{*}{$<0.001$} \\
\hline No & $1232(96.8)$ & 398 (95.9) & & $516(93.0)$ & \\
\hline \multicolumn{6}{|l|}{ Gestational age } \\
\hline Preterm & 88 (6.9) & $22(5.3)$ & \multirow{2}{*}{0.248} & 33 (5.9) & \multirow{2}{*}{0.444} \\
\hline$>37$ weeks & 1185 (93.1) & 393 (94.7) & & $522(94.1)$ & \\
\hline
\end{tabular}

Table 2. Pregnancy outcomes of term, nulliparous women, according to their pre-pregnancy body mass index (BMI).

\begin{tabular}{|c|c|c|c|c|c|}
\hline Variable & $\begin{array}{c}\text { Normal BMI } \\
\text { N = } 1273 \text { n (\%) }\end{array}$ & $\begin{array}{c}\text { Overweight BMI } \\
\mathrm{N}=415 \mathrm{n}(\%)\end{array}$ & P-value & $\begin{array}{c}\text { Obese BMI } \\
\text { N = } 555 \text { n (\%) }\end{array}$ & P-value \\
\hline \multicolumn{6}{|l|}{ Method of delivery } \\
\hline Normal delivery & $983(77.2)$ & $286(68.9)$ & & $353(63.6)$ & \\
\hline Instrumental-assisted vaginal & $143(11.2)$ & $59(14.2)$ & \multirow{2}{*}{0.003} & $61(11.0)$ & \multirow{2}{*}{$<0.001$} \\
\hline Elective CS & $19(1.5)$ & $5(1.2)$ & & $12(2.2)$ & \\
\hline Emergency CS & $128(10.1)$ & 65 (15.7) & & $129(23.2)$ & \\
\hline \multicolumn{6}{|l|}{ Indication of emergency CS } \\
\hline No progress at labor & $62(4.9)$ & $24(5.8)$ & 0.462 & $60(10.8)$ & $<0.001$ \\
\hline Fetal distress & $49(3.8)$ & $32(7.7)$ & \multirow[t]{2}{*}{0.001} & $51(9.2)$ & \multirow[t]{2}{*}{$<0.001$} \\
\hline Mal presentation & $9(0.7)$ & $2(0.5)$ & & $5(0.9)$ & \\
\hline Pregnancy induced hypertension (PIH) & $4(0.3)$ & $1(0.2)$ & & - & \\
\hline Failed induction & $2(0.2)$ & $2(0.5)$ & & $4(0.7)$ & \\
\hline Maternal request & - & $2(0.5)$ & & $1(0.2)$ & \\
\hline \multicolumn{6}{|l|}{ Birth weight } \\
\hline$<4000$ gm & $1238(97.3)$ & 399 (96.1) & \multirow{2}{*}{0.253} & $514(92.6)$ & \multirow{2}{*}{$<0.001$} \\
\hline$\geq 4000 \mathrm{gm}$ & $35(2.7)$ & $16(3.9)$ & & $41(7.4)$ & \\
\hline
\end{tabular}

creased prevalence of cesarean section as well as assisted vaginal delivery in these patients may be related to increased maternal pelvic soft tissue, which narrows the diameters of the birth canal and increases the risk associated with dystocia [7]. Vahratian et al. also suggested that increased risk of cesarean deliveries in obese patients could be related to difference in the progress of labor or their response to the oxytocin therapy [2]. The higher incidence of meconium staining, cord accidents, macrosomic infants and increased incidence of fetal dis- 
tress might be contributing for the increase prevalence of cesarean section in these obese patients [5] [6] [8].

In our study we found that the prevalence of large for gestational age infants is higher in obese nulliparous. Pedersen hypothesized that the increased glucose concentration in obese mother led to fetal hyperglycemia and hyperinsulinaemia causing increased fetal growth [9]. Obese pregnant patients have insulin resistant even in the absence of diabetes mellitus, and this patient has higher fasting plasma triglyceride levels with a greater leucine turn over. The triglycerides are energy rich and placental lipase can cleave triglyceride and transfer the free fatty acid to the fetus [10]. These above factors may be responsible for macrosomic fetus in obese parturient.

Our obese pregnant patient has a significantly higher rate of chronic wound infection and dehiscence. Wall et al. also reported the higher incidence of wound complication [11].

When pregnancy occurs in obese women with or without bariatric surgery; pregnancies after bariatric surgery are less likely to be complicated with gestational diabetes, pre-eclampsia and fetal macrosomia [12].

\section{Conclusion}

Maternal obesity leads to prepartum, peripartum as well as fetal complication. Obese nulliparous pregnant patients had a significant risk of developing gestational diabetes and pregnancy induced hypertension. In these patients the prevalence of assisted vaginal and cesarean deliveries is significantly higher; when compared to normal weight the obese nulliparous patient had a higher risk of having macrosomal fetus.

\section{References}

[1] http://qatarsweetepidemic.org

[2] Vahratian, A., Siega-Riz, A.M., Savitz, D.A. and Zhang, J. (2005) Maternal Pre-Pregnancy Overweight and Obesity and the Risk of Cesarean Delivery in Nulliparous Women. Annals of Epidemiology, 15, 467-474. http://dx.doi.org/10.1016/j.annepidem.2005.02.005

[3] Chu, S.Y., Kim, S.Y., Schmid, C.H., Dietz, P.M., Callaghan, W.M., Lau, J. and Curtis, K.M. (2007) Maternal Obesity and Risk of Cesarean Delivery: A Meta-Analysis. Obesity Reviews, 8, 385-394. http://dx.doi.org/10.1111/j.1467-789X.2007.00397.x

[4] Flegal, K.M., Carroll, M.D., Kit, B.K. and Ogden, C.L. (2012) Prevalence of Obesity and Trends in the Distribution of Body Mass Index among US Adults 1999-2010. JAMA, 307, 491-497. http://dx.doi.org/10.1001/jama.2012.39

[5] Sebire, N.J., Jolly, M., Harris, J.P., Wadsworth, J., Joffe, M., Beard, R.W., et al. (2001) Maternal Obesity and Pregnancy Outcome: A Study of 287213 Pregnancies in London. International Journal of Obesity, 25, 1175-1182. http://dx.doi.org/10.1038/sj.ijo.0801670

[6] Cnattingius, R., Cnattingius, S. and Nortzon, F.C. (1998) Obstacles to Reducing Cesarean Rates in a Low-Cesarean Setting: The Effect of Maternal Age, Height and Weight. Obstetrics \& Gynecology, 92, 501-506. http://dx.doi.org/10.1016/S0029-7844(98)00244-0

[7] Young, T.K. and Woodmansee, B. (2002) Factors That Are Associated with Cesarean Delivery in Large Private Practice. The Importance of Prepragnancy Body Mass Index and Weight Gain. American Journal of Obstetrics \& Gynecology, 187, 312-318. http://dx.doi.org/10.1067/mob.2002.126200

[8] Kaiser, P.S. and Kirby, R.S. (2001) Obesity as a Risk Factor for Cesarean in a Low Risk Population. Obstetrics \& Gynecology, 97, 39-43. http://dx.doi.org/10.1016/S0029-7844(00)01078-4

[9] Pedersen, J., Bojsen-Moller, B. and Poulsen, H. (1954) Blood Sugar in New Born Infants of Diabetic Mothers. Acta Endocrinologica, 15, 33-52.

[10] Thomas, C.R. (1987) Placental Transfer of Non-Esterified Fatty Acid in Normal and Diabetic Pregnancy. Biology of the Neonate, 51, 91-101.

[11] Wall, P.D., Deucy, E.E., Glant, J.C. and Pressman, E.K. (2003) Vertical Skin Incisions and Wound Complications in Obese Parturient. Obstetrics \& Gynecology, 102, 952-956. http://dx.doi.org/10.1016/S0029-7844(03)00861-5

[12] (2013) American College of OBGY Committee Opinion No. 549. 